\title{
Construção Ativa do Conhecimento: Experiência em um Centro Universitário de São Paulo, SP
}

\author{
Maria Elisa Gonzalez Manso* \\ Doutora em Ciências Sociais PUCSP, Pós-graduada em Docência em Saúde UFRGS, Médica. Docente \\ de Gerontologia da Coordenadoria Geral de Especialização, Aperfeiçoamento e Extensão da pontifícia \\ Universidade Católica de São Paulo, Cogeae-PUC-SP, e de Medicina do Centro Universitário São Camilo, SP
}

* Autora para correspondência: mansomeg@hotmail.com

\section{RESUMO}

Formar profissionais médicos com perfil mais humanístico, crítico, que se responsabilizem pelo sujeito que os procura em um momento de sofrimento, que se voltem para as necessidades de saúde desse indivíduo e que estejam comprometidos com a população para a qual trabalham é o desafio atual dos cursos de Medicina. Este relato refere-se a uma experiência na construção ativa do conhecimento discente dentro de conteúdos curriculares afeitos à área de humanidades e do cuidado interdisciplinar ao idoso, nem sempre valorizados pelos ingressantes como necessários para sua formação técnico-instrumental, mas fundamentais para o trabalho na Atenção Básica em Saúde. O desenvolvimento do material teve como pressuposto a Aprendizagem Baseada em Projetos, e, nas palavras dos próprios educandos, a construção do material fez com que temas não considerados inicialmente relevantes por eles para a adequada atenção à saúde do idoso, já que não estavam diretamente relacionados ao tratamento das doenças físicas que acometem esse segmento etário, fossem reconhecidos como indispensáveis. Família, rede social, meio ambiente, políticas públicas, direitos, demografia, epidemiologia, sociologia e antropologia foram abordados, estudados e interconectados em uma visão do processo de adoecimento mais ampla e adequada às necessidades desse grupo populacional. Acreditando que o conhecimento se constrói ativamente, outras experiências relacionadas ao ensino baseado em projetos vêm sendo desenvolvidas junto ao curso aqui citado.

Palavras-Chave: Aprendizagem Ativa; Ensino Médico; Currículo Profissional.

\begin{abstract}
Training humanistic and critic medical professionals who take responsability for the person that looks for them at a time of suffering, who care about individual health necessities and that is committed to the people they work for is the current challenge of medical courses. This report refers to an experience in the active construction of student knowledge within curricular contents related to the humanities and interdisciplinary care areas to the elderly, something not always valued by the students as necessary for their technical-instrumental training, but fundamental for the work in Primary Health Care. The development of the material was based on Project-Based Learning and, in the words of the students themselves, the construction of the material caused subjects that were not initially considered relevant by them in order to provide adequate attention to the elderly's health, since they were not directly related to the treatment of physical diseases that affect this age segment. These subjects were, then, recognized as important and indispensable. Family, social networks, environment, public policies, rights, demography, epidemiology, sociology and anthropology were approached, studied and interconnected in a more broad and adequate vision of the process of sickness in this population group. Believing that knowledge is actively built, other experiences related to teaching based on projects have been developed along the course mentioned here.
\end{abstract}

Keywords: Active Learning; Medical Education; Professional Curriculum.

\section{Introdução}

A formação dos profissionais da área da saúde vem sendo questionada já há algumas décadas, principalmente no que tange ao ensino médico, considerado inadaptado às necessidades e às demandas populacionais, desresponsabilizado, 
fragmentado, hiperespecializado, altamente tecnologizado, desumanizado (FRENK et al., 2010; UFRGS, 2014).

Este é um problema discutido em todo o mundo, mas, no Brasil, perpassa ainda pelas iniquidades da atenção. A cada ano mais profissionais médicos entram no mercado de trabalho desejando apenas atender em hospitais dotados de alta tecnologia, concentrando-se nas grandes capitais e não considerando o sistema público de saúde (SUS) como seu local de trabalho (Cremesp, 2015).

Os graduandos já adentram o curso médico com uma visão inscrita na cultura que prioriza o saber técnico na sua formação. Imbuídos dessa construção cultural, a discussão de determinados temas e conteúdos curriculares é tida pelos educandos como não sendo essencial para seu preparo enquanto profissionais. Dentre esses temas, as humanidades, consideradas até o século passado como opcionais à formação médica, são as que provocam maior resistência, assim como as especialidades que demandam um olhar interdisciplinar e mais cuidador, por exemplo a medicina de família e a geriatria (AYRES et al., 2013; CUNHA et al., 2014) Vencer esse pré-conceito torna-se instigante para o professor.

O saber médico, entretanto, deve ser pautado no binômio competência/cuidado, em que a primeira diz respeito ao conhecimento cognitivo e competência técnica, enquanto o segundo trata da compaixão, empatia, atitudes, relações. Hoje em dia, há uma tendência a esse binômio ser tratado como uma polaridade, com inclinação para o primeiro polo, técnico, em detrimento do segundo, não técnico. A graduação médica deve voltar-se para reconfigurar um equilíbrio entre esses polos (GADAMER, 2011; AYRES et al., 2013; MANSO, 2015).

A grande maioria dos problemas de saúde das populações são atendidos conforme a denominada Atenção Básica de Saúde (ABS), em que os profissionais exercem a medicina voltada para o sujeito adoecido, segundo os princípios que norteiam a constituição do SUS: integralidade da atenção à saúde, interprofissionalidade, equidade da atenção, dentre outros. Formar médicos que se voltem para a ABS e não apenas para a atenção hospitalar é, portanto, o grande desafio dos cursos de graduação em Medicina (CNES, 2014; UFRGS, 2014).

Desde 2001 as Diretrizes Curriculares Nacionais (DCN) para os cursos de Medicina, revistas em 2014, vêm sendo modificadas com essa finalidade. Definindo o perfil do egresso como mais humanístico, crítico e voltado para as necessidades populacionais, propõem a inserção precoce dos educandos no SUS enquanto cenário de prática e ressaltam que o perfil do egresso deve ser adaptado às necessidades de saúde das populações a serem atendidas. Nessas diretrizes, o papel das metodologias ativas de aprendizagem é destacado (STREIT, 2012; GNES, 2014).

A mudança da graduação em Medicina perpassa não apenas pela modificação do currículo médico, mas principalmente pela reconstrução do conhecimento pelos discentes, que necessitam descobrir significado, pessoal e próprio, no que estão aprendendo, relacionar novas informações com as que já possuem, com as novas exigências que o exercício de sua profissão lhes coloca e com as necessidades da população com a qual vão trabalhar (GIMENO SACRISTÁN, 2001).

A aprendizagem é um processo de crescimento e desenvolvimento de uma pessoa em sua totalidade e envolve, portanto, aspectos tanto relacionados com o conhecimento técnico quanto afetivo-emocionais, de habilidades humanas e profissionais e de atitudes ou valores (MASETTO, 2015). Aprendemos quando sentimos necessidade daquilo, quando insatisfeitos, quando consideramos o conteúdo relevante e desafiador, e é essa aprendizagem que modifica as pessoas.

Assim, motivar alunos, tornar o ambiente da sala de aula dinâmico, utilizar outros espaços de encontros e convivência como espaços de aprendizagem, trabalhar com feedback, dentre outros princípios da andragogia, tornam a aprendizagem colaborativa, oportunizando a reconstrução do conhecimento e propiciando não apenas a formação de profissionais, mas acima de tudo de cidadãos (GAETA \& MASETTO, 2013; UFRGS, 2014). 
A utilização de ferramentas e métodos ativos de construção do saber discente é um valioso auxiliar na consecução dessa tarefa. Destarte, o professor torna-se um mediador e o encontro professor-aluno motivador, já que ambos aprendem juntos, em um espaço de interação, ambos sujeitos da aprendizagem.

Este relato refere-se a uma experiência na construção ativa do conhecimento discente dentro de conteúdos curriculares afeitos à área de humanidades e do cuidado interdisciplinar ao idoso, nem sempre valorizados pelos ingressantes como necessários para sua formação técnico-instrumental, mas fundamentais para o trabalho na ABS.

\section{Descrição da Experiência}

Esta experiência deu-se através da produção de material didático, no caso um manual, pelos próprios educandos do curso de Medicina do Centro Universitário São Camilo, Cusc-SP.

O Manual da Liga de Estudos do Processo do Envelhecimento (Lepe) contou com 22 discentes autores, matriculados entre o terceiro e o décimo semestre do curso, que desenvolveram pesquisas e construíram junto com dois professores-orientadores treze capítulos sobre o processo de envelhecer. Esses capítulos versaram sobre temas considerados, em sua maioria, pelos graduandos como "não médicos". Apresentam-se os temas trabalhados no quadro 1.

Tais temas foram definidos em conjunto pelos docentes e discentes participantes, estes últimos posteriormente divididos em duplas, de acordo com a afinidade pelo assunto a ser desenvolvido. Além dos temas, um cronograma de entregas foi estabelecido.

A partir daí os educandos desenvolveram suas pesquisas (documentais, revisão bibliográfica) e necessitaram recorrer a outros profissionais presentes na equipe de saúde, tais como nutricionistas, fisioterapeutas, enfermeiros, construindo-se assim um saber interprofissional que foi posteriormente transformado em capítulos. Estes eram enviados aos orientadores, os quais verificavam não apenas a adequação de conteúdo, mas o andamento do processo, a redação, a obediência às normas e o trabalho do grupo, dando feedbacks frequentes sobre o trabalho.

Durante o processo, dois graduandos deixaram de participar da construção e alguns educandos participaram na confecção de mais de um capítulo. Os próprios discentes foram provocados a avaliarem seu trabalho e o dos demais membros do grupo, principalmente no que tange ao cumprimento de prazos e à qualidade da escrita e do conteúdo apresentados.

Este livro foi construído no período de um ano, editado e lançado oficialmente, com a presença de familiares dos participantes, durante a realização do Congresso Acadêmico do curso, realizado em São Paulo, em outubro de 2014. A figura 1 mostra o livro editado, a figura 2 traz um pôster elaborado por alunos e apresentado em congresso que descreve a metodologia até aqui narrada, e a figura 3 traz a foto de parte dos graduandos-autores.

Esse manual passou a fazer parte do material didático recomendado pelo curso desde então e encontra-se disponibilizado à venda em livrarias e em congressos sobre envelhecimento, cuja renda é revertida para o Centro Acadêmico do curso, sendo utilizada na realização de eventos científicos, dentre os quais o próprio Congresso Acadêmico. Essa experiência resultou no planejamento pelos próprios graduandos de novos volumes, estes em andamento.

\section{Resultados e Discussão}

Carabetta Júnior destaca que a especialização possibilitou à universidade autonomia e democratização, mas também trouxe consigo vários problemas. Assim, ocorreram "a proliferação de especialidades; a duplicação de disciplinas; o isolamento entre os departamentos; os currículos extensos e, muitas vezes, superficiais; a ausência de comunicação entre cursos e ensino frequentemente desprovido de motivação para o enfrentamento de desafios" (CARABETTA JÚNIOR, 2016, p. 116). Superar essas adversidades, reconhecendo o educando como sujeito do seu conhecimento e centro da aprendizagem, impõe que conteúdos 
GERIATRIA

\section{MANUAL DA LEPE}

Liga de Estudos do Processo de Envelhecimento

\section{EDITORAS}

- Maria Elisa Gonzalez Manso

- Elaine Cristina Alves Biffi

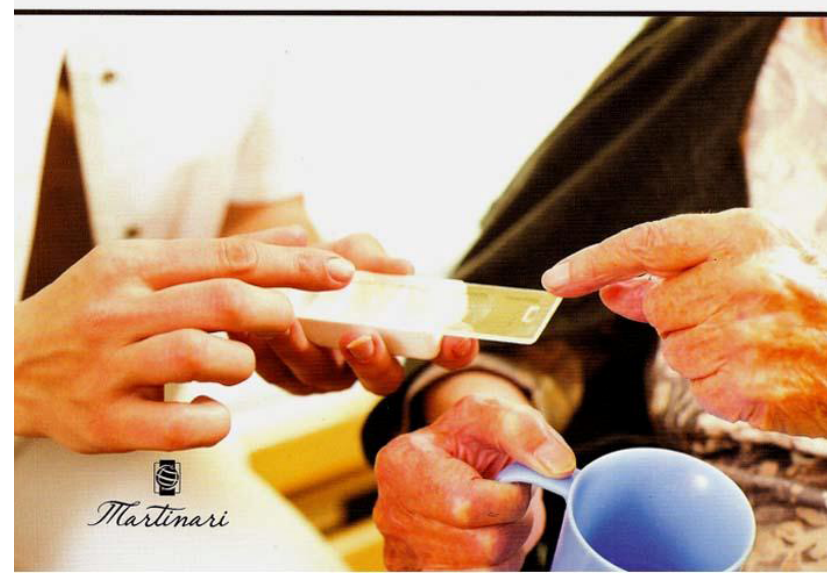

Figura 1 - Capa do livro "Manual da Liga de Estudos do Processo do Envelhecimento".

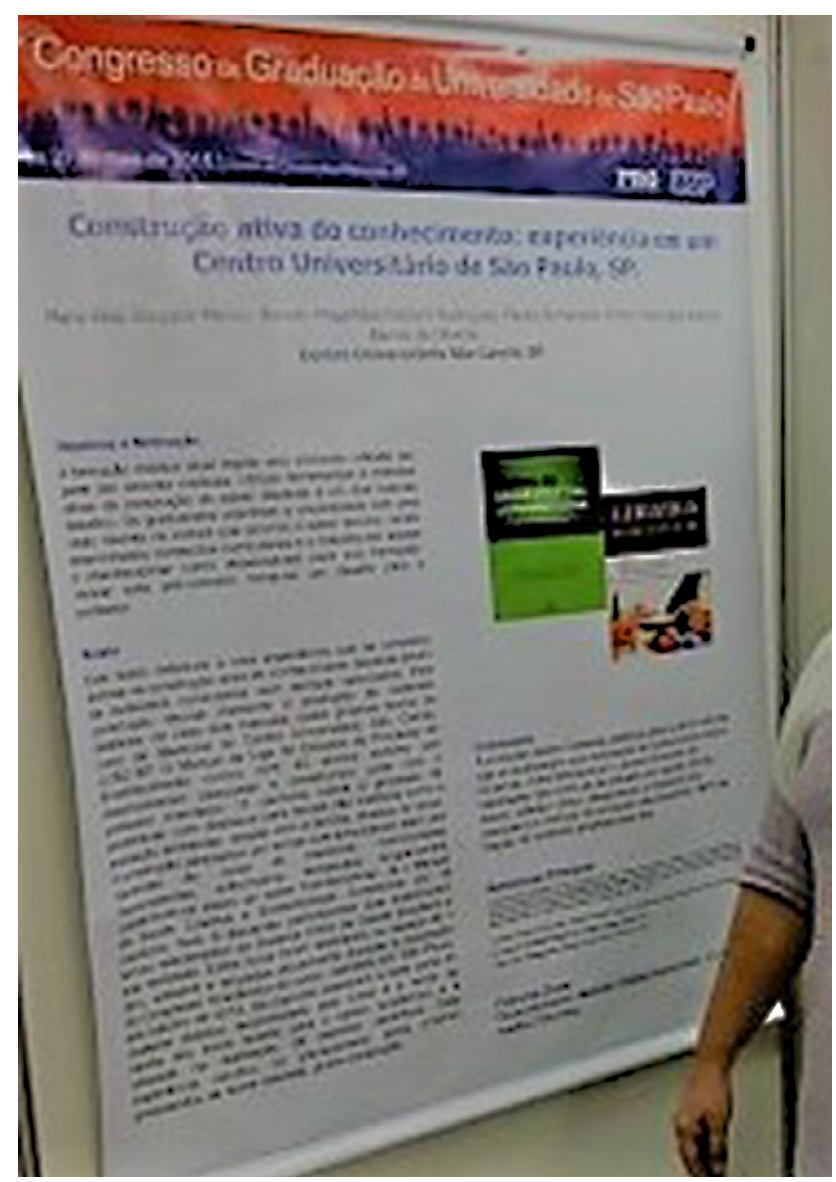

Figura 2 - Pôster apresentado no Congresso de Graduação da USP.

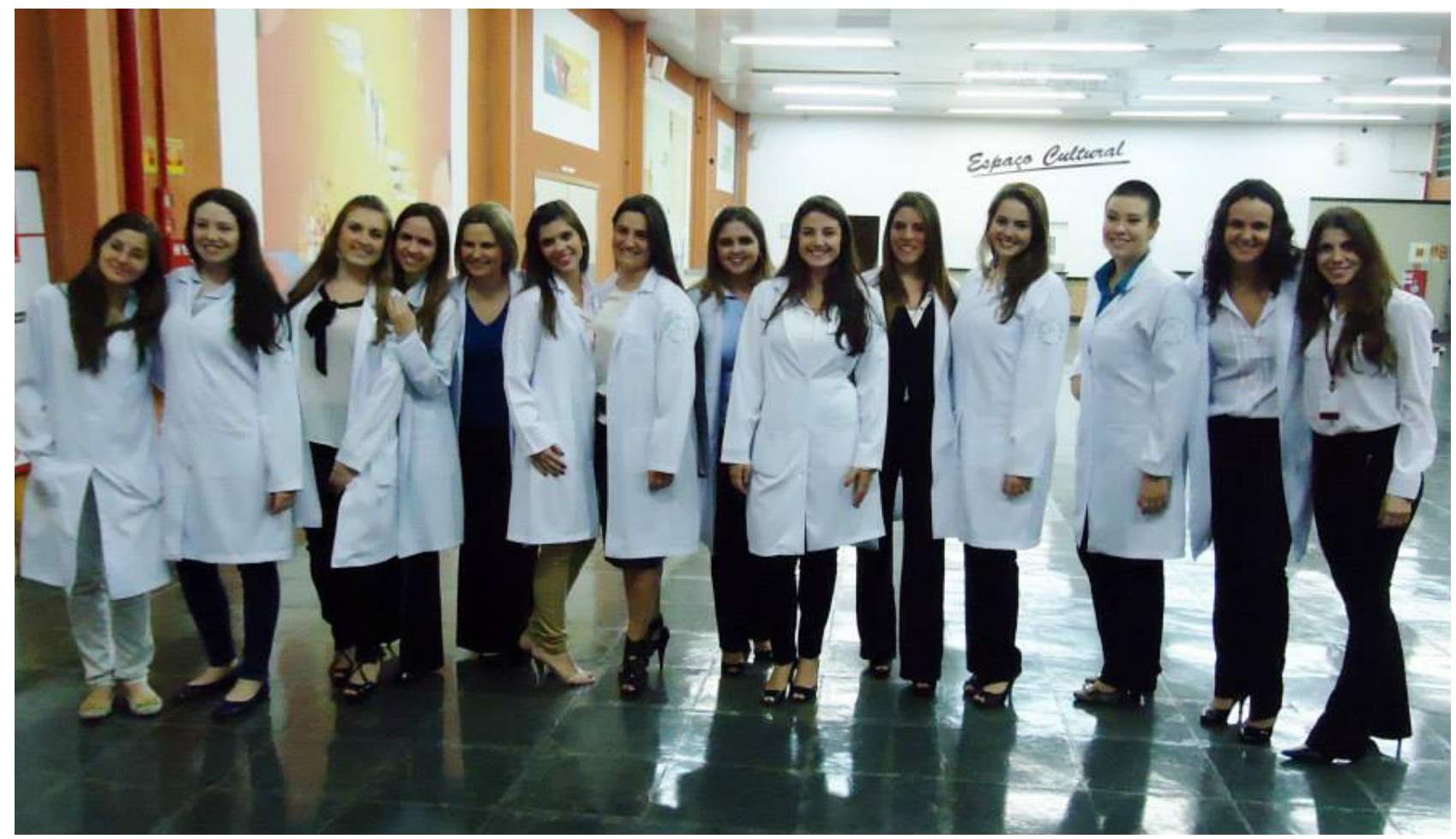

Figura 3 - Parte do conjunto de autoras da publicação. 


\section{Temas}

Aspectos demográficos e epidemiológicos do envelhecimento

O processo normal de envelhecer

Qualidade de vida na velhice

Anamnese e exame físico do idoso

Avaliação da capacidade funcional

Avaliação cognitiva e do humor

Avaliação da marcha, equilíbrio e atividade física no idoso

Avaliação nutricional

Aspectos farmacológicos no envelhecimento

Avaliação ambiental

O cuidador

Serviços de saúde para idosos

Políticas públicas e os idosos

\section{Área(s) profissional(ais) envolvida(s)}

Demografia; Epidemiologia

Fisiologia

Psicologia; Antropologia

Gerontologia

Fisioterapia

Psicologia

Fisioterapia; Educação física

Nutrição

Farmacologia

Serviço social

Enfermagem

Serviço social; Administração

Serviço social; Direito

Quadro 1 - Temas trabalhados durante a confecção do material didático e profissionais envolvidos, Cusc SP, 2014.

curriculares possam ser trabalhados de forma integrada e superando a fragmentação.

No que tange ao ensino médico, é fundamental que o professor pense em utilizar recursos didáticos que favoreçam o perfil generalista, ético, humanista e crítico que se deseja do egresso. Este, como um profissional que entende a integralidade da atenção não apenas enquanto atuação de um único profissional de saúde, deve perceber a importância da interprofissionalidade e como esta permite a compreensão do processo saúde-doença daquele sujeito singular. Daí, como citado, a relevância das metodologias ativas de aprendizado.
São considerados bons métodos ativos de educação aqueles que se baseiam na aprendizagem significativa; que favoreçam a construção do conhecimento em grupo; que proporcionem atividades integradas a outras disciplinas; que permitam entender a aplicação do conhecimento na realidade; que fortaleçam princípios éticos; que estimulem o educando a buscar aprofundamento de modo a entender as limitações das informações que chegam até ele; que despertem a curiosidade e a autonomia (aprender a aprender); que estejam integrados ao contexto social; que trabalhem e valorizem a emoção e, por fim, que estimulem o 
estudante a buscar soluções (FARIAS et al., 2015).

Há vários métodos que podem ser aplicados, destacando-se, na área do ensino em saúde, a Aprendizagem Baseada em Problemas, a Aprendizagem em Equipes, a Problematização e a Aprendizagem Baseada em Projetos. Esta última, considerada com níveis taxonômicos elevados, por desenvolver a capacidade criativa e a autonomia dos estudantes, tem atividades que giram em torno de um projeto que deve ser executado e transformado em produto final, envolvendo conhecimentos variados e favorecendo a interdisciplinaridade. Nessa metodologia, o papel do educador é de estimular e mediar, sempre privilegiando o interesse grupal, pois somente assim haverá participação nas diferentes etapas (FARIAS et al., 2015). A experiência ora apresentada utilizou pressupostos da Aprendizagem Baseada em Projetos, sendo considerado como produto final o próprio material didático transformado em livro.

Nas palavras dos próprios educandos, a construção do Manual da Lepe fez com que temas não tidos inicialmente como relevantes por eles para a adequada atenção à saúde do idoso, já que não estavam diretamente relacionados ao tratamento das doenças físicas que acometem esse segmento etário, fossem reconhecidos como indispensáveis. Família, rede social, meio ambiente, políticas públicas, direitos, demografia, epidemiologia, sociologia e antropologia foram abordados, estudados e interconectados em uma visão do processo de adoecimento mais ampla e adequada às necessidades desse grupo populacional.

Dos alunos envolvidos no processo, a grande maioria (dezessete - 85\%) já se encontra formada e inserida no mercado de trabalho. Destes, três se voltaram para o trabalho na ABS e duas egressas para a Geriatria.

O material desenvolvido obteve ainda boa aceitação pelo público e permanece até hoje disponível em livrarias e, como mencionado, em uso pelos novos graduandos que adentram no curso.

Das dificuldades encontradas durante o desenvolvimento do projeto, destacam-se as frequentes interrupções. Como a proposta curricular da ins- tituição não prevê a utilização da metodologia baseada em projetos, apenas Aprendizagem Baseada em Problemas, os educandos e professores tiveram que disponibilizar horários de trabalho além do previsto na carga horária do curso, o que causou alguns atrasos no cronograma e sobrecarga de trabalho. A literatura ressalta que as metodologias ativas de aprendizado devem estar integradas no currículo como um todo, sendo que a utilização alternada das mesmas produz os melhores resultados (FARIAS et al., 2015).

Além do mais, notou-se uma dificuldade significativa por parte de algumas duplas de educandos na escrita do material, demandando inúmeras reescritas. $\mathrm{O}$ fato de os discentes terem que avaliar seus colegas também trouxe algum desconforto ao grupo de graduandos, demandando conversas, grupais e individuais, do docente-orientador sobre o que é o processo avaliativo e quais suas finalidades. O dar e o receber feedback mostraram-se desafiadores durante o processo.

\section{Conclusão}

A produção deste material didático pelos próprios alunos não só propiciou uma ampliação do conhecimento técnico sobre os temas, como favoreceu o desenvolvimento de habilidades tais como as de trabalho em equipe, escrita, leitura, reflexão crítica, dar e receber feedback. Como citado, o trabalho interprofissional e interdisciplinar foi valorizado e ocorreu uma sensibilização dos graduandos para a ABS e para o cuidado, conforme proposto nas diretrizes curriculares, o que pode ser observado pela inserção dos egressos no mercado de trabalho.

Acreditando que o conhecimento se constrói ativamente, outras experiências relacionadas com o ensino baseado em projetos vêm sendo desenvolvidas junto ao curso aqui citado. Dentre essas, destaca-se o projeto denominado "Ensino Médico Baseado em Narrativas", em andamento, agraciado com o prêmio Inovasus Gestão da Educação em Saúde 2015 e que vem sendo financiado pela Organização Pan-Americana de Saúde (Opas). 


\section{Referências bibliográficas}

AYRES, J. R. C. M.; RIOS, I. C.; SCHRAIBER, L. B; FALCÄO, M. T. C. \& MOTA, A. "Humanidades como Disciplina da Graduação em Medicina". Revista Brasileira de Educaşão Médica, vol. 37, pp. 455-463, 2013.

CARABETTA JÚNIOR, V. "Metodologia Ativa na Educação Médica". Revista de Medicina (São Paulo), vol. 95, n. 3, pp. 113-121, 2016.

CONSELHO NACIONAL DE EDUCAÇÃO. Câmara Educação Superior. "Diretrizes Curriculares Nacionais do Curso de Graduação em Medicina-Parecer CNE/CES No 116/2014”. Brasília, CNES: 2014.

CONSELHO REGIONAL DE MEDICINA DE SÃO PAULO, Cremesp. "Dados da pesquisa Demografia Médica no Brasil são apresentados em coletiva à imprensa em Brasília". Disponível em: http://www.cremesp.org.br/?siteAcao $=$ NoticiasC\&id $=2761$. Acessado em: 21 out. 2015

GUNHA, A.C.N.P.; GUNHA, N.N.P. \& BARBOSA, M.T. "Geriatric Teaching in Brazilian Medical Schools in 2013 and Considerations Regarding Adjustment to Demographic and Epidemiological Transition". Revista Associação Médica Brasileira. vol. 62, n. 2, pp.179-183, 2014.

FARIAS, P. A. M; MARTIN, A. L. A. R. \& CRISTO, C. S. "Aprendizagem Ativa na Educação em Saúde: Percurso Histórico e Aplicações". Revista
Brasileira de Educaşão Médica, vol. 39, pp. 143-158, 2015.

FRENK, J.; CHEN, L.; BHUTTA, Z. G. A.; COHEN, J.; CRISP, N.; EVANS, T.; FINEBERG, H.; GARCIA, P.; KE, Y. et al. "Health Professionals for a New Century: Transforming Education to Strengthen Health Systems in an Interdependent World". Lancet, vol. 376, pp. 1923-1958, 2010.

GADAMER, Hans-Georg. O Caráter Oculto da Saúde. 2 ed. Rio de Janeiro: Vozes, 2011.

GAETA, C. \& MASETTO, M. T. O Professor Iniciante no Ensino Superior: Aprender, Atuar e Inovar. São Paulo: Senac, 2013.

GIMENO SACRISTAN, J. O Currículo: uma Reflexão sobre a Prática. Porto Alegre: Artmed, 2001.

MANSO, M. E. G. Saúde e Doensa: do Controle sobre os Corpos à Perspectiva do Adoecido. São Paulo: Max Limonad, 2015.

MASETTO, M. T. Desafios para a Docência Universitária na Contemporaneidade: Professor-Aluno em Inter-Ação Adulta. São Paulo: Avercamp, 2015.

STREIT, D. S.; NETO, F. B.; LAMPERT, J. B.; LEMOS, J. M. G. \& BATISTA, N. A. Dez Anos de Diretrizes Curriculares Nacionais. Rio de Janeiro: Abem, 2012.

UNIVERSIDADE Federal do Rio Grande do Sul. Currículo, Inovacōes Educacionais e Prática Docente em Saúde. Porto Alegre: UFRGS/EducaSaúde, 2014. Disponível em: $<$ https://moodle.ufrgs.br>. Acessado em 16 set. 2014.

Publicado em 22/12/2017. 